\title{
STUDIES OF A SCOTTISH DRIFT SOIL.
}

PART III.

\author{
By WILLIAM GAMMIE OGG, M.A., B.Sc. \\ AND JAMES HENDRICK, B.Sc. \\ (Department of Agricultural Research, University of Aberdeen.)
}

\section{The Absorptive Power of Powdered Granite and a comparison with Craibstone SoIL.}

IT has been shown in Part II that a glacial drift soil in a comparatively unweathered condition has a considerable power of absorption for ammonia, although it has sometimes been held that it is the weathered material in soils that is responsible for the absorptive power. Glacial drift, as exemplified in the Craibstone soil, however, though its weathering is geologically recent compared with that of many English soils, has been subjected to age-long weathering since the glacial period, and in the process of soil formation a certain amount of weathering with the resultant decomposition has necessarily taken place. Craibstone soil has also been shown (Table II, Part II) to contain a fairly large percentage of organic matter and it might be contended that the absorptive power was chiefly due to either or both of these factors.

To prove or disprove this directly would be a very difficult matter, but it is possible to show whether a comparable substance which has not undergone weathering to any appreciable extent and is free from organic matter has a similar absorptive power. This is by no means a new line of inquiry. In an attempt to determine the substance in soils on which absorption depends, Way (1) turned his attention "to the compound silicates present in clay and derived from the granitic rocks to which clay owes its origin. Fragments of such rocks are found in clay, e.g. Felspar-double silicate of alumina and potash; albite-a double silicate of alumina and soda; also a similar double silicate of alumina and lime. These different natural silicates finely powdered were digested in a solution of $\mathrm{NH}_{4} \mathrm{Cl}$ but none of them possessed the power of com- 
bining with its ammonia. It is not, therefore, to the undecomposed remains of the granitic rocks that the absorptive power of clay is to be referred."

Since Way's time, however, several investigators have shown that when salt solutions come in contact with certain minerals, a portion of the base is removed from solution. Sullivan (2), who has carried out a series of investigations on this subject with special reference to geologic phenomena writes, "With this in view, some of the changes that take place at ordinary temperature when water solutions are brought into contact with rock-forming minerals have been examined. The result has been in a word to make it apparent that the chemical reaction between silicates and salt solutions is a very general phenomenon, taking place to a decided extent immediately upon contact, and that the outcome is mainly an exchange of bases in chemically equivalent quantities between solid and solution; the metal of the dissolved salt is precipitated and an equivalent quantity of silicate is decomposed and its basès enter the solution. Salt solutions as decomposing agents are much more active than pure water and are comparable with acids in this respect."

From chemical analysis of mechanical separates (Part I of this paper (3)) from a mineralogical examination, and from a consideration of its origin it has been concluded that Craibstone soil contains a considerable proportion of little-weathered material. As it was impossible to separate the weathered from the unweathered and to remove the organic matter, a comparable substance unweathered and free from organic matter was sought for, and since the soil was derived from granitic material, granite was chosen.

The material used was obtained from Dancing Cairns quarries near Aberdeen and is a typical granite containing quartz, orthoclase, oligoclase, black mica, and white mica. It consisted of powder ground from granite rubble at the quarries by a factory which prepares artificial paving stones from granite dust and cement. The sample used was therefore a roughly ground powder prepared by mechanical means from granite.

It consisted of material of all sizes from pieces with a diameter of three to four millimetres down to the finest dust. For comparison with the soil, this was subjected to a mechanical analysis with distilled water, as described in Part II of this paper; the fractions obtained corresponding to "fine gravel" (3-1 mm.), "coarse sand" (1-2 mm.), "fine sand" $(\cdot 2-04 \mathrm{~mm}$.), "silt" (.04-.01 mm.), "fine silt" (.01-.002 mm.) and "clay" (below $.002 \mathrm{~mm}$.). 


\section{Absorption of Ammonta by Powdered Granite.}

The absorption of ammonia from a solution of ammonium sulphate was determined for these fractions as in the case of the corresponding fractions of Craibstone soil (see Part II of this paper).

There were again limitations as regards perfect separation of the fractions and method of estimating the absorption though the absence of organic matter and other material binding the particles together rendered the separation much simpler than in the case of soil. The final results are expressed only to the third decimal place.

\section{Table I. Absorption by Powdered Granite.}

\begin{tabular}{lllc} 
Fraction & \multicolumn{2}{c}{$\begin{array}{c}\text { Absorption by } 10 \text { grms. of } \\
\text { material from 50 c.c. of } \\
\text { solution of ammonium } \\
\text { sulphate (grms. nitrogen) }\end{array}$} \\
Fine gravel... & $\ldots$ & - \\
Coarse sand & $\ldots$ & .001 \\
Fine sand & $\ldots$ & $\ldots$ & .002 \\
Silt $\ldots$ & $\ldots$ & $\ldots$ & .004 \\
Fine silt & $\ldots$ & $\ldots$ & .011 \\
Clay & $\ldots$ & $\ldots$ & .021
\end{tabular}

From these results it is evident that powdered granite has a considerable power of absorbing ammonia from a solution of ammonium sulphate, and as would naturally be expected this power is by far the greatest in the finest fractions.

A comparison of the relative surfaces exposed by the different fractions is interesting in this connection.

If it is assumed that the particles are all spherical and have a specific gravity of 2.65 and if the mean diameter of the particles in each fraction be taken, the surface of any weight of a fraction can be calculated from the following formula.

$$
\text { Surface }=\frac{w t . \times 4 \pi r^{2}}{\text { spec. grav. } \times \frac{4}{3} \pi r^{3}}=\frac{\text { wt. } \times 3}{\text { spec. grav. } \times r} .
$$

It is impossible to draw any conclusions as to the connection between surface and absorptive power, for the different fractions almost certainly differ in chemical composition, and also no allowance was made for the falling off in absorption as ammonia was removed and the solution became weaker.

The actual particles are not uniform spheres, but are of infinite variability and the surfaces are much greater than shown. Besides, as 
Sullivan points out, the surface actually exposed to a salt solution even in the case of a fresh rock in situ, is perhaps greater than is apparent, and in the material under consideration, the fractures caused by the grinding must have further increased the surface.

Table II.

Absorption and Theoretical Surface of Granite Fractions.

\begin{tabular}{|c|c|c|}
\hline Fraction & $\begin{array}{l}\text { Surface per } 10 \text { grms. } \\
\text { (sq. cms.) }\end{array}$ & $\begin{array}{l}\text { Absorption per } 10 \text { grms. } \\
\text { from solution of } \\
\text { ammonium sulphate } \\
\text { (grms. nitrogen) }\end{array}$ \\
\hline Fine gravel & $\ldots \quad 113$ & - \\
\hline Coarse sand & 377 & .001 \\
\hline Fine sand & 1887 & .002 \\
\hline Silt $\quad \ldots$ & 9057 & .004 \\
\hline Fine silt & 37,736 & .011 \\
\hline Clay ... & 226,415 & .021 \\
\hline
\end{tabular}

It may however be assumed that the surface varies inversely as the mean diameter, as in the case of regular figures. If we calculate on this assumption we arrive at the figures shown in Table III.

Table III.

\begin{tabular}{|c|c|c|c|c|c|}
\hline & & $\begin{array}{l}\text { Mean diameter } \\
(\mathrm{mm} \text {.) }\end{array}$ & Proportion & Inverse & $\begin{array}{c}\text { Actual absorption } \\
\text { proportion found } \\
\text { by experiment }\end{array}$ \\
\hline Coarse sand & $\ldots$ & .7 & 700 & 1 & 1 \\
\hline Fine sand & $\ldots$ & $\cdot 12$ & 120 & 6 & 2 \\
\hline Silt $\quad \ldots$ & $\ldots$ & .025 & 25 & 28 & 4 \\
\hline Fine silt & $\ldots$ & .006 & 6 & 116 & 11 \\
\hline Clay ... & $\ldots$ & .001 & 1 & 700 & 21 \\
\hline
\end{tabular}

In Table III the column headed "Inverse" shows approximately the inverse proportions of the mean diameters, and it will be seen that the actual absorption found in the case of the different fractions is not even approximately proportional to these inverse proportions. For instance the "fine silt" and "clay" have mean diameters which bear the ratio to one another of approximately 6 to 1 . The "clay" should therefore have about six times the surface of the "fine silt," but its absorptive power is only about twice as great as that found for the "fine silt." Somewhat similar results are found in the other cases. The evidence, therefore, so far as it goes, indicates that the absorption does not vary proportionally to the surface, though as the surface becomes greater the absorption becomes greater, but at a much lower rate. 


\section{Comparison of the Absorptive Power of the Soll and Grantte Fractions.}

In comparing the soil and the granite fractions we must take account of the following differences:

1. The soil contains humus and the granite does not. The granite has on that account, however, a greater mineral surface.

2. Through weathering agencies the soil constituents have undergone some decomposition while the granite may be taken as almost unweathered.

3. In the processes of weathering and grinding, and also in the course of mechanical analysis, the various fractions of soil and granite have to some extent become sorted out into material of different chemical composition.

4. The soil constituents may have already absorbed a certain amount of ammonia before the sample was taken from the field. Bearing these differences in mind, we give the comparison in Table IV.

Table IV.

Comparison of the Absorptive Power of Soil and

Granite Fractions.

\begin{tabular}{|c|c|c|c|c|}
\hline \multicolumn{2}{|c|}{ Fraction } & Granite & Soil & $\begin{array}{c}\% \text { humus in soil } \\
\text { (chromic acid method) }\end{array}$ \\
\hline Fine gravel... & $\cdots$ & - & .001 & 1.0 \\
\hline Cosrse sand & $\ldots$ & .001 & .001 & $0 \cdot 9$ \\
\hline Fine sand $\ldots$ & $\ldots$ & .002 & .003 & 0.9 \\
\hline Silt $\ldots \quad \ldots$ & ... & .004 & .010 & $9 \cdot 5$ \\
\hline Fine silt & $\ldots$ & .011 & .015 & $20 \cdot 7$ \\
\hline Clay... & $\ldots$ & .021 & .017 & $24 \cdot 5$ \\
\hline
\end{tabular}

The comparison brings out a general similarity between the absorptions of the soil and the granite fractions.

The fraction of granite corresponding to "clay" has an absorption higher than that of "clay" from Craibstone soil, and weight for weight of mineral matter nearly as high an absorption even supposing organic matter took no part and the whole of the soil absorption was due to the mineral matter.

The absorption by "fine silt," though less than that by the corresponding soil fraction is fairly high, indicating that "fine silt" in soils apart from the organic matter, may play an important part in absorption.

The cosrser fractions are much less important and the large difference in the "silts" may be chiefly due to the presence of humus in the soil fraction, though the evidence does not point that way. 
With so many unknown and varying factors it is difficult to draw any detailed conclusions from the comparison, but it seems legitimate to conclude that unweathered mineral particles when they occur in soils may take a very considerable part in soil absorption.

\section{Absorption after Ignition.}

As Way pointed out in 1852 , the power of a soil to combine with ammonia is greatly reduced by burning it. "It would seem the more strongly the soils were burnt, the more completely was their absorptive power destroyed."

Experiments by Way on a clay containing no vegetable matter nor oxide of iron (from a pit 20 feet below the surface) showed a large absorptive power. After heating strongly for two hours in a covered crucible, the absorptive power was sensibly diminished though anything but destroyed. Way also tried the effect of heat on the artificial double silicates which he prepared, and found that after being heated to redness they no longer absorbed ammonia.

Table V. Comparison of the Absorptive Power after Ignition.

\begin{tabular}{|c|c|c|c|c|c|c|c|c|}
\hline \multirow[b]{2}{*}{ Fraction } & \multicolumn{2}{|c|}{$\begin{array}{l}\% \text { loss of weight } \\
\text { on ignition }\end{array}$} & \multicolumn{2}{|c|}{$\begin{array}{l}\text { Absorption per } \\
10 \text { grms. } \\
\text { before ignition } \\
\text { (grms. nitrogen) }\end{array}$} & \multicolumn{2}{|c|}{$\begin{array}{l}\text { Absorption per } \\
10 \text { grms. } \\
\text { after ignition } \\
\text { (grms. nitrogen) }\end{array}$} & \multicolumn{2}{|c|}{$\begin{array}{l}\text { Absorption by } \\
\text { equal weigh ts } \\
\text { (10 grms.) } \\
\text { ignited material } \\
\text { (grms. nitrogen) }\end{array}$} \\
\hline & Soil & Granite & Soil & Granite & Soil & Granite & Soil & Granite \\
\hline ine gravel & 1.38 & 0.48 & .001 & 一 & - & - & - & - \\
\hline loarse sand & 1.07 & 0.66 & .001 & .001 & - & - & - & -- \\
\hline Fine sand & $1 \cdot 36$ & 0.86 & .003 & .002 & .001 & .001 & .001 & .001 \\
\hline & $\ldots 11.81$ & $1 \cdot 05$ & $\cdot 010$ & .004 & .002 & $\cdot 002$ & .003 & .002 \\
\hline & $\ldots \quad 28.52$ & 3.01 & .015 & .011 & .004 & .006 & .006 & .006 \\
\hline Ylay & $\ldots 34 \cdot 59$ & 6.96 & .017 & .021 & .005 & .013 & .007 & .014 \\
\hline
\end{tabular}

He concluded that this was due to their losing water of combination. "It is only in the state of hydrates that the double silicates possess the property in question, and this again accounts for the fact that the retentive power of clay and soils in general for ammonia was very much diminished and in some cases entirely destroyed after the soils had been heated to redness."

To see if it would throw any light on the share taken by undecomposed mineral matter in absorption by Craibstone soil, the fractions of soil and granite were ignited and the absorptions after ignition compared.

The organic matter in the soil is destroyed by ignition and the absorptive power of the fractions consequently lowered, but if the 
absorption due to mineral constituents is of the same nature in both cases, then after ignition equal weights of soil and granite fractions might be expected to show a similar absorptive power.

To compare the absorption of soil and granite after ignition the fractions were ignited over a Bunsen at a low red heat and the absorption determined as before by shaking up with a solution of ammonium sulphate containing 5 gms. $\left(\mathrm{NH}_{4}\right)_{2} \mathrm{SO}_{4}$ per litre.

The chief points brought out by the comparison are

1. The absorptive power of both soil and granite is very much reduced by ignition.

2. The lowering of the absorption is much greater for soil than for granite.

3. Calculating what would be the absorption by equal weights of ignited material, it is found that the soil and granite fractions are very similar except in the case of "clay" which has its absorption very much further reduced for soil than for granite.

\section{Retention of Absorbed Ammonia by Unweathered Materiat.}

Several investigators have shown that material absorbed by soils is very firmly retained and is not readily removed by water. In regard to this Way (4) writes in 1852 "Whatever may be the form of combination in which ammonia is retained, it is plainly in an insoluble state."

A. Voelcker (5) in 1860 carried out a series of experiments on ammonia retention, and concluded that "In no instance is the ammonia absorbed by soils from solutions of free ammonia or from ammoniacal salts so completely or permanently fixed as to prevent water from washing out appreciable quantities of the ammonia... but the power of soils to remove ammonia from solution is very much greater than their property of yielding it again to water." Retention of absorbed materials probably depends largely on the nature of the soil. In cases where large amounts of organic matter and weathered material are present, these may have the chief share in the retention, and light sandy soils without much humus are generally held to have little power of retaining manures. It has been shown that powdered granite has a considerable absorptive power for ammonia, but this would have little practical value unless accompanied by some power of retention, and to determine whether the absorbed ammonia is readily removed by water, a percolation experiment was carried out.

The finest fractions of granite which have by far the greatest absorptive power could not be used for this purpose on account of the time 


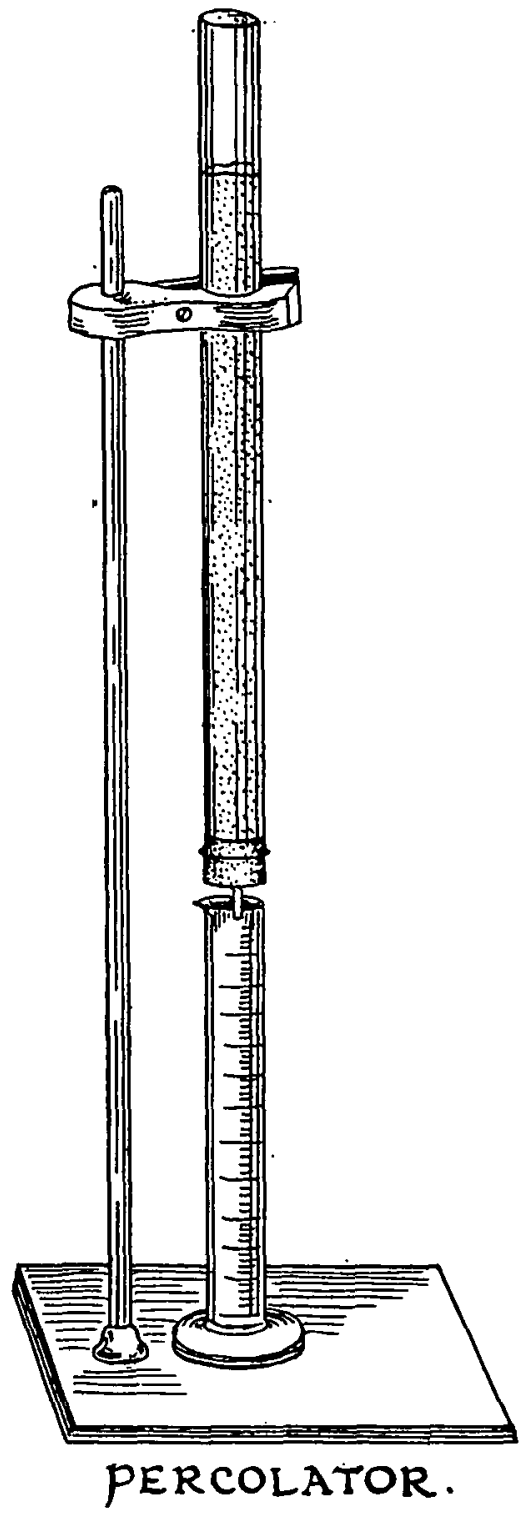

Used for Powdered Gravite. 
required for the solution to pass through, and also because of its tendency to form channels and not pass evenly. The material used was passed through a sieve with 100 meshes per linear inch, and included all the fractions finer than coarse sand.

The percolator consisted of a glass tube of $2.5 \mathrm{~cm}$. diam. and 100 grms. of the granite occupied a height of about $21 \mathrm{cms}$. A solution of ammonium sulphate containing 5 grms. per litre was percolated through the column of granite 20 c.c. at a time, and this was continued until the solution came through practically unchanged.

The percolate began to run on the third addition of 20 c.c. of solution and nitrogen was determined as before, by distillation with magnesia, in every 20 c.c. of percolate.

\section{Table VI. Absorption of Ammonia by Powdered Granite.}

$\begin{array}{ccc}\begin{array}{c}\text { Number of } \\ \text { percolste }\end{array} & \begin{array}{c}\text { Grms. nitrogen in } \\ 20 \text { c.c. peroolate }\end{array} & \begin{array}{c}\text { Grms. nitrogen } \\ \text { retained by granite }\end{array} \\ 1 & .0004 & .0214 \\ 2 & .0062 & .0370 \\ 3 & .0172 & .0416 \\ 4 & .0199 & .0435 \\ 5 & .0204 & .0449 \\ 6 & .0207 & .0460 \\ 7 & .0210 & .0468 \\ 8 & .0211 & .0475 \\ 9 & .0213 & .0480 \\ 10 & .0214 & .0484 \\ 11 & .0214 & .0488 \\ 12 & .0215 & .0491 \\ 13 & .0196 & .0513)\end{array}$

It will be seen from the table that the ammonia was almost totally removed from the first 20 c.c. that passed. As more solution flowed through, the amount of nitrogen in the percolate increased; until, when the thirteenth addition had been made, the tenth 20 c.c. of percolate came away practically unchanged. Percolation with ammonium sulphate solution was stopped at this point.

20 c.c. of the ammonium sulphate solution contained 0218 grms. of nitrogen and by subtracting the amount of nitrogen in every 20 c.c. of the percolate from this figure, the total amount retained after each addition of solution, was ascertained.

Sulphate was determined in the first five portions of the percolate and it was found none had been retained. 


\section{Removal of the Ammonta by Water.}

An attempt was now made to remove the ammonia by percolating distilled water 20 c.c. at a time, through the column.

Thirteen additions of ammonium sulphate solution had been made, but as it required slightly more than 40 c.c. of solution to saturate the granite, it was not until the third lot of distilled water had been added, that thirteen portions of percolate of 20 c.c. each were obtained.

The washing out of absorbed ammonia therefore properly began with the fourteenth portion, and there was present in the granite dust at this point, the total nitrogen added less the sum of the nitrogen recovered in the first thirteen portions of percolate $(\cdot 0218 \times 13-\cdot 2321=\cdot 0513$ gms. N). Percolation with water was continued until the percolates were practically free from nitrogen. The results are shown in Table VII.

As will be seen from the table, there was a gradual but comparatively slow removal of the absorbed ammonia-the rate of washing out falling off, until, when about $20 \%$ of the total amount absorbed remained, the amount removed by 20 c.c. distilled water was practically negligible.

This bears out the conclusion arrived at by Voelcker for soils that the rate of washing out is slow compared with the rate of absorption. It would also appear that even where the absorption in soils is due to unweathered mineral matter there is little risk of appreciable quantities of absorbed ammonia being washed out.

The granite was removed from the percolator and the nitrogen retained determined by distillation with magnesia as before. This gave .0048 gms. nitrogen which left only $.0072-\cdot 0048=\cdot 0024$ gms. nitrogen unaccounted for. The conditions of the experiment. were quite unfavourable to nitrification, and the balance was probably fixed in a less easily decomposable form.

It is difficult to determine in what form the ammonia is retained. Way (6) from his experiments on artificial silicates concluded that an almost insoluble double ammonium silicate was formed. Voelcker (7) and others have shown that when ammonium sulphate is added to the soil as manure, an insoluble nitrogenous compound is formed which remains in the soil while the calcium sulphate washes out in the drainage water.

Russell (8) found that the compound formed is not completely decomposed on distillation with magnesia and concludes that it does not seem to be an ordinary ammonium compound.

Since the sulphate is not retained by the soil or granite, but merely 
the base, some other base must come through or free sulphuric acid be produced.

Table VII.

Removal of Ammonia from Powdered Granite by Distilled Water.

\begin{tabular}{|c|c|c|}
\hline $\begin{array}{l}\text { Number of } \\
\text { percolate }\end{array}$ & $\begin{array}{l}\text { Grms. nitrogen in } \\
20 \text { c.c. percolate }\end{array}$ & $\begin{array}{l}\text { Grms. nitrogen } \\
\text { retained by granite }\end{array}$ \\
\hline 14 & .0048 & .0465 \\
\hline 15 & .0042 & .0423 \\
\hline 16 & .0028 & .0395 \\
\hline 17 & .0022 & .0373 \\
\hline 18 & .0022 & .0351 \\
\hline 19 & .0018 & .0333 \\
\hline 20 & .0017 & .0316 \\
\hline 21 & .0017 & .0299 \\
\hline 22 & .0014 & .0285 \\
\hline 23 & .0014 & .0271 \\
\hline 24 & .0014 & .0257 \\
\hline 25 & .0013 & .0243 \\
\hline 26 & .0013 & .0229 \\
\hline 27 & .0013 & .0216 \\
\hline 28 & .0012 & .0204 \\
\hline 29 & .0012 & .0192 \\
\hline 30 & .0010 & .0182 \\
\hline 31 & -0010 & .0172 \\
\hline 32 & .0010 & .0162 \\
\hline 33 & .0010 & .0152 \\
\hline 34 & .0009 & .0143 \\
\hline 35 & .0007 & .0136 \\
\hline 36 & .0007 & .0129 \\
\hline 37 & .0007 & .0122 \\
\hline 38 & .0006 & .0116 \\
\hline 39 & .0006 & .0110 \\
\hline 40 & .0006 & .0104 \\
\hline 41 & .0005 & .0099 \\
\hline 42 & .0005 & .0095 \\
\hline 43 & .0004 & .0091 \\
\hline 44 & .0004 & .0087 \\
\hline 45 & .0003 & $\cdot 0084$ \\
\hline 46 & .0003 & .0081 \\
\hline 47 & .0003 & .0078 \\
\hline 48 & .0002 & .0076 \\
\hline 49 . & .0002 & .0074 \\
\hline 50 & .0002 & .0072 \\
\hline
\end{tabular}

The percolates with powdered granite showed no acidity to litmus, so that if free acid was produced it must have combined with other bases present in the granite. Analysis of a solution obtained by shaking 
up a quantity of granite dust with ammonium sulphate solutions and filtering off the granite, showed that the base which chiefly replaced the ammonium was calcium. There was also an increase in potassium, sodium, magnesium and silica compared with a solution from the same quantity of granite dust and distilled water.

These results throw little light on the means of retention. But whatever be the mode, there is certainly a considerable power of absorption by powdered granite, and the ammonia so retained is not readily washed out. From the results of the percolation experiment it seems likely that the absorption by unweathered material at any rate is largely an adsorption effect-addition of solution causing a decrease in surface tension and a concentration of ammonia in the surface layer; addition of water increasing the surface tension and diminishing the concentration in the surface layer, i.e. negative adsorption.

\section{Conclusions.}

1. Powdered granite in a finely divided condition has a very considerable absorptive power.

2. Compared with fractions from Craibstone soil, granite fractions have a similar power of absorbing ammonia and it would appear that absorption is not by any means due to weathered materials, alone, but that unweathered materials have quite as great an absorptive effect.

3. The evidence indicates that the absorption does not increase proportionately to the increase of the surface with fractions of increasing fineness, but at a lower rate than the increase of surface.

4. After ignition there is a reduction in the absorptive power and this reduction is more marked in the case of the soil fractions.

5. The absorbed ammonia is only gradually washed out by water, but the whole of it is not removed in this way-a point being reached when practically no more ammonia is removed.

6. Absorption by powdered granite and probably also by the unweathered or little weathered materials in soils, seems to be largely an adsorption effect.

Publication of Parts II and III of this paper was delayed by the war. Since they were drafted a valuable résumé of the subject by Prescott has appeared in Vol. virr of this Journal. 
Absorption by 10 gram portions of the various fractions of powdered granite from a solution of $\mathrm{mm}$

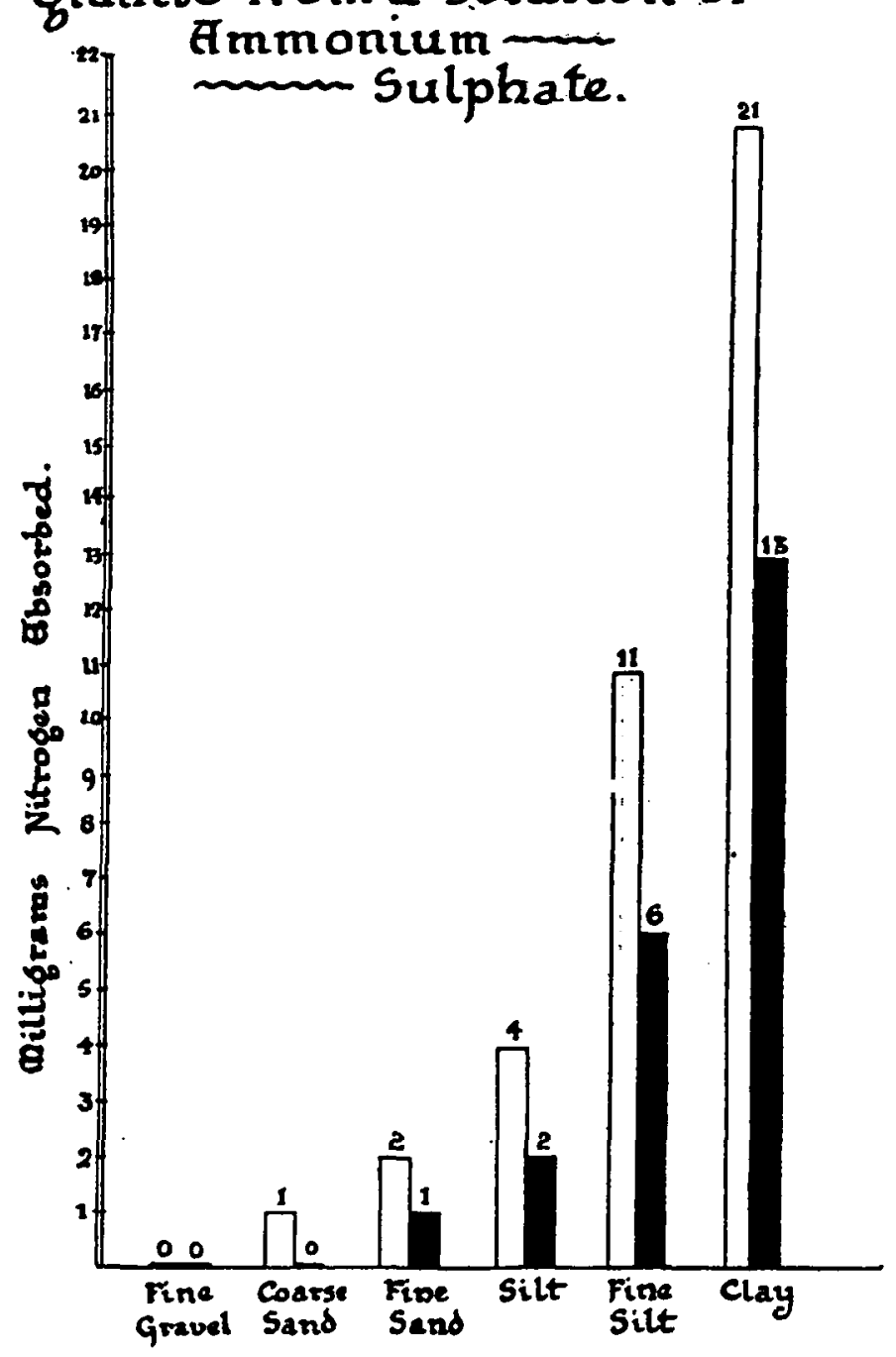

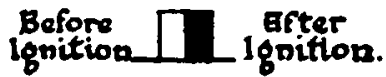


Elbsorption by 10 grams of the Various fractions of Soil \& Granite from 50 ces of a solution containing 5 Grams $\left(\mathrm{NH}_{4}\right)_{2} \mathrm{SO}_{4}$ per Litre.

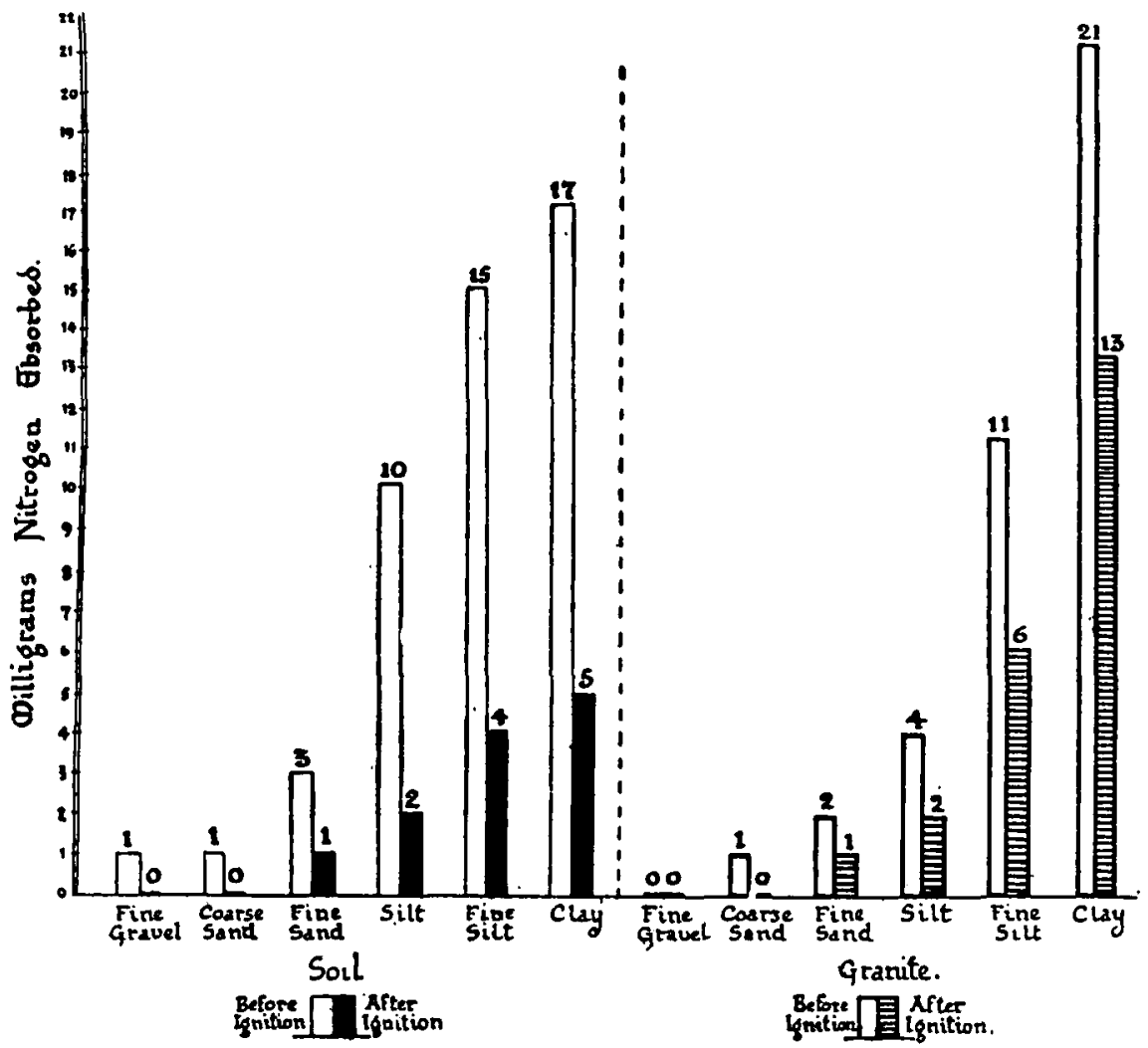


Absorption of Ammonia by powdered Granite \& Subsequent Cuashing Out by Distilled Water.

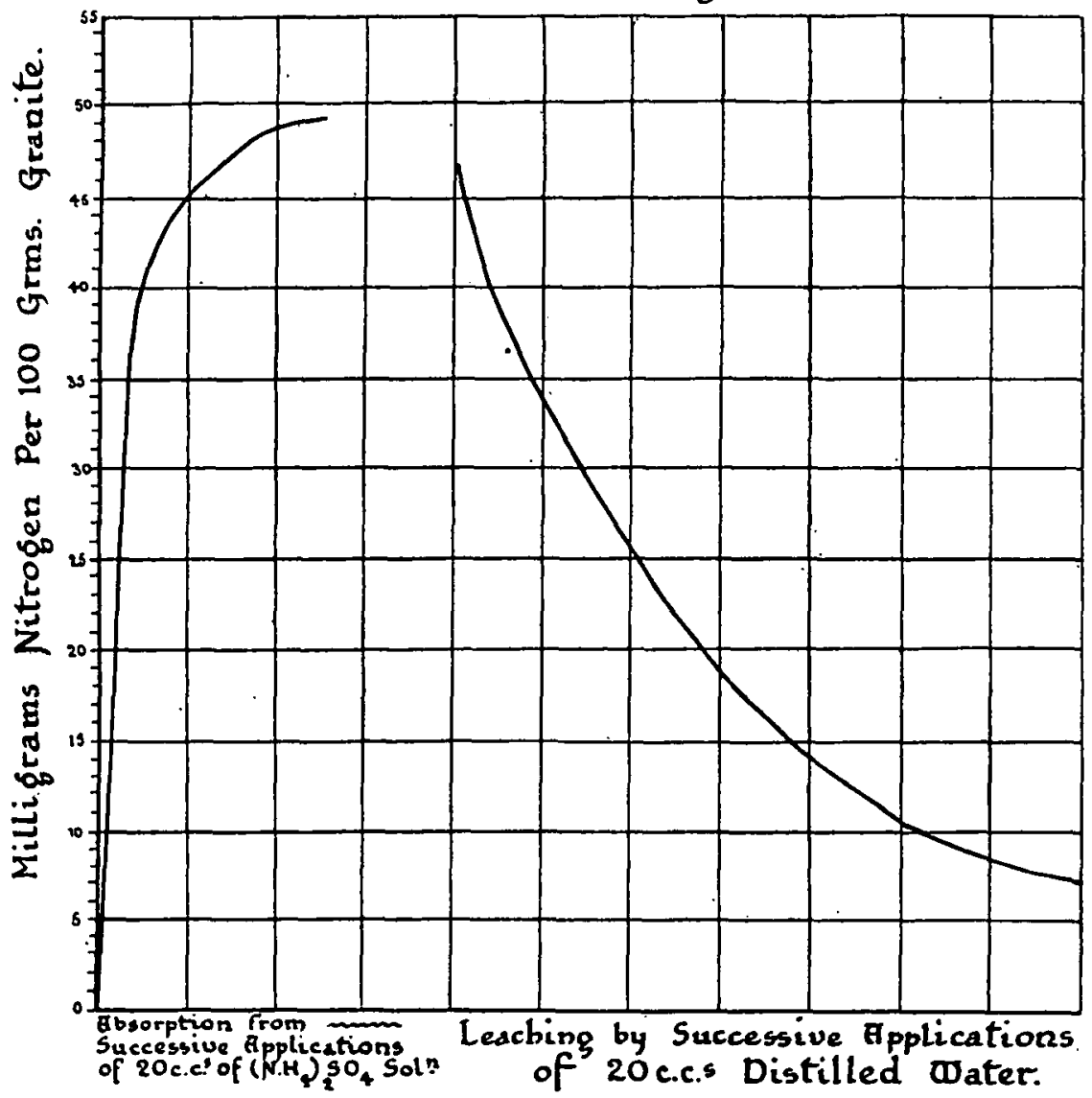

REFERENCES.

(1) Journ. of the Roy. Agr. Soc. 1852,13, 123-143.

(2) The Interaction between Minerals and Water Solutions, 1907, Bul. 312. U.S. Geol. Survey.

(3) Journ. of Agr. Sci. 1916, 7, 458-469.

(4) Loc. cit.

(5) Journ. Roy. Agr. Soc. 1860, 21, 105-134.

(6) Loc. cit.

(7) Journ. Roy. Agr. Soc. 1860, 21, 105-134.

(8) Journ. Agr. Sci. 1910, 3, 233-245.

(Received December 30th, 1919.) 